\title{
BACTERIAL ETIOLOGY OF BRONCHOALVEOLAR LAVAGE FLUID IN TERTIARY CARE PATIENTS AND ANTIBIOGRAM OF THE ISOLATES
}

\author{
Sanjib Adhikari ${ }^{1,2}$, Ramesh Sharma Regmi ${ }^{1,2}$, Siddanta Pandey ${ }^{1}$, Parash Paudel ${ }^{1}$, Nischal Neupane ${ }^{1}$, Shyam \\ Chalise $^{1}$, Ashok Dubey ${ }^{1}$, Sarad Chandra Kafle ${ }^{1}$, Komal Raj Rijal ${ }^{2^{*}}$ \\ ${ }^{1}$ Department of Microbiology, Birendra Multiple Campus, Tribhuvan University, Bharatpur, Nepal \\ ${ }^{2}$ Central Department of Microbiology, Tribhuvan University, Kirtipur, Kathmandu, Nepal \\ *Corresponding author: rijalkomal@gmail.com
}

(Received: March 11, 2021; Revised: May 16, 2021; Re-revised: June 08, 2021; Accepted: June 08, 2021)

\begin{abstract}
Bronchoalveolar Lavage (BAL) is a medical technique by which cells and fluids from bronchioles and lung alveoli are withdrawn for diagnosis of disease or evaluation of treatment. Patients with various pulmonary infections follow the procedure of BAL for the disease diagnosis as it has high sensitivity and reliability in diagnosis. To examine the bacterial etiology of BAL fluids among tertiary care patients with pulmonary infections, a cross-sectional study was conducted over a period of three months from August to November 2018. A total of 149 BAL fluid samples were examined and the bacterial agents were isolated and identified by conventional microbiological methods. Out of the 149 samples, 142 samples were culture positive. Among 6 different isolates (4 Gram-negative and 2 Gram-positive), Pseudomonas aeruginosa (45\%) was predominant followed by Klebsiella pneumoniae $(25.3 \%)$. A higher infection rate was seen among males $(62.4 \%)$ and in the age group 60-70 years (30.0\%). In addition, $25.4 \%(36 / 149)$ samples were positive in Acid Fast staining. Bacterial recovery from the BAL fluid was significantly associated with the gender and age of the patients $(\mathrm{p}<0.05)$. Gentamycin was the least resisted $(1.5 \%)$ by Gram-negative isolates followed by Polymyxin-B $(3 \%)$. For Gram-positive isolates, Ofloxacin was the most effective drug resisted by none of the isolates followed by Gentamycin. Among the 157 isolates, 125 (79.6\%) were MDR and $35.0 \%$ of Enterobacteriaceae were ESBL producers. Detection of bacterial agents from BAL fluid can be a basis for successful antimicrobial therapy for patients with pulmonary infections.
\end{abstract}

Keywords: AFB, Bacterial characterization, BAL, MDR, Pulmonary infection.

\section{INTRODUCTION}

Bronchoalveolar lavage (BAL) is a medical procedure in which cells and fluids from bronchioles and lung alveoli are extracted for disease diagnosis (Henderson, 1994). BAL is performed by bronchoscope, the fiber optic wire that is wedged into a bronchus, and sterile saline is pumped in and then withdrawn along with the fluid and cells for analysis (Henderson, 1994). Bronchoalveolar lavage can play a significant role in the diagnosis of various diseases like pulmonary infections, pulmonary malignancy, acute respiratory failure, diffuse infiltrative lung disease, occupational lung disease, pediatric lung disease, post-transplant monitoring of the lung allograft, pediatric lung disease, and others (Meyer, 2007).

In clinical associated pneumonia patients, the treatment failure has been observed which might be linked with the inappropriate choice of the antibiotics, development of superimposed infection due to hospital-acquired pathogens or acquisition of drug-resistant pathogens from the community (Arancibia et al., 2000), and the inconclusive sputum culture report might further mislead the diagnosis (Magazine et al., 2013). The detection of definite etiologic agents is the basis for successful antimicrobial therapy; hence, uncontaminated and appropriate samples for bacteriological diagnosis are of utmost importance. The sample collection using the BAL technique increases the efficacy of the actual pathogen detection by reducing the chances of contamination and is highly convenient for pediatric patients $(<5$ years old $)$ as the sputum collection is very difficult in such patients (García-Elorriagaa et al., 2015). Likewise, in immunocompromised patients, the treatment of bacterial pneumonia is still troublesome due to the inabilities of most of the patients to produce sputum (Kahn \& Jones, 1987). Therefore, the BAL technique is one of the best options for the proper diagnosis of the disease.

Several microorganisms such as Pseudomonas aeruginosa, Klebsiella pneumoniae, Staphylococcus aureus, Acinetobacter, Streptococcus pneumoniae, Escherichia coli, Enterobacter, Haemophilus influenzae, Moraxella, Citrobacter, Nocardia, and many others have been reported from BAL fluid (Magazine et al., 2013). The drug resistance among the clinical (Adhikari et al., 2019; Duwadi et al., 2020; Gyawali et al., 2020; Regmi et al., 2020) and non-clinical isolates (Adhikari et al., 2020; Khadka et al., 2018; Sapkota et al., 2019, 2020) have been widely reported in many studies and bacterial isolates present in the BAL fluid have also been found resistant to the arrays of commonly used antibiotics (Magazine et al., 2013). Bacterial pathogens such as methicillin-resistant $S$. aureus (MRSA), Acinetobacter baumannii, $P$. 
aeruginosa, Stenotrophomonas maltophilia, Enterobacter aerogenes, methicillin-resistant Staphylococcus epidermidis (MRSE), methicillin-resistant Staphylococcus hemolyticus (MRSH), Enterococcus faecium, Burkholderia cepacia isolated from BAL fluid are found to be MDR (Kim et al., 2012). ESBL-producing bacteria have also been abundantly isolated from both clinical samples (Önnberg et al., 2011; Nasrin et al., 2010) and non-clinical samples (Sapkota et al., 2019).

Furthermore, in developing countries like Nepal, the prevalence of pulmonary diseases like tuberculosis (Banstola, 2012) and pneumonia (Haque, 2019) has created serious problems regarding the high rate of morbidity and mortality. People of all age groups have suffered from those diseases. Due to the lack of proper management and medication, the disease is transmitted from person to person easily. Since the people are not much aware of the threat and possible harms of the disease, they do not follow proper sanitation and medication habits leading to mortality and morbidity. One of the major factors leading to illness is the lack of proper and reliable disease detection techniques. BAL is one of the best innovational techniques discovered which brought a huge breakthrough in the world's medicine. It is a faster, easier, reliable, and sensitive technique in pulmonary disease diagnosis. In light of this discussion, the current study aims to investigate the bacterial spectra of BAL fluid along with the antibiotic resistance patterns of the isolates from the patients attending BPKMCH, Bharatpur.

\section{MATERIALS AND METHODS}

\section{Study site and study period}

A prospective laboratory-based cross-sectional study was carried out at the Microbiology Laboratory of BP Koirala Memorial Cancer Hospital, Bharatpur, Chitwan. The study was conducted over a period of three months, from August to November 2018.

\section{Sample size, inclusion, and exclusion criteria}

A total of 149 BAL fluid samples were collected from the bronchoscopy ward out of the patients suffering from pulmonary infections attending the minor OT Department of BPKMCH for bronchoscopy. The BAL procedures were carried out by the trained medical staff of the hospital. Patients of all age groups and sex were included in the study. Cultures showing mono-microbial growth were included in the study. Samples with improper sealing and labeling were excluded from the study.

\section{Data and specimen collection}

Verbal informed consent was sought from each patient before sample collection. They were assured of the fact that the data collected will be used solely for research and their information would be kept confidential. A pre- structured questionnaire comprising of age, sex, ethnicity, and details regarding bronchoscopy was used to gather the information. Before sample analysis, the BAL fluid was transported to the microbiology laboratory by the registered assistant. The container was first checked whether it was sealed or not or if it was provided with proper labeling with name, age, sex, etc. The sample was properly labeled with the sample number. Then the appropriate samples were considered for further processing without any delay to avoid probable contamination or desiccation.

\section{Sample processing}

The sample was processed as soon as it reached the microbiology laboratory following the standard laboratory procedures. The samples were divided into two parts-one was used for preparing smears for direct microscopy while the other was used for culture. Two smears were prepared from each sample for Gram staining and acidfast staining.

\section{Macroscopic and microscopic examination}

The BAL fluids were examined for their appearance, color, consistency, and presence of debris. An even smear of the most purulent part of the specimen was prepared on clean and grease-free slides and subjected to Gram staining and acid-fast staining. The specimen was also observed for any kind of pus cells.

\section{Culture of specimen}

The aerobic culture of the specimen was performed under the aseptic condition as soon as the specimen reached the laboratory. The sample was inoculated on MacConkey Agar (MA) and Blood Agar (BA) plates. The plates were aerobically incubated at $37^{\circ} \mathrm{C}$ for 24 hours. If no growth was observed, then the sample was reported as growth negative. In case of bacterial growth, a single isolated colony was taken and sub-cultured in Nutrient Agar (NA) and incubated at $37^{\circ} \mathrm{C}$ for $24 \mathrm{~h}$ aerobically (Isenberg, 2016).

\section{Isolation and identification of bacteria}

The identification of bacterial isolates was done using standard microbiological techniques as described in Bergey's Manual of Systemic Bacteriology which comprised of studying the colonial morphology, physiological tests, staining reactions, and various biochemical tests (Bergey et al., 1984). Each organism was obtained in its pure form for performing biochemical and other tests. Gram staining of the isolated culture was performed from the primary culture. Appropriate biochemical tests were performed to identify the organism by its phenotypic characterization. Catalase test, oxidase test, coagulase test, nitrate reduction test, oxidative/fermentative test, triple sugar iron test, SIM test, 
MR/VP test, citrate utilization test, urease test were performed as needed (Forbes et al., 2007).

\section{Antibiotics susceptibility testing of bacterial isolates}

Bacterial susceptibility test to antimicrobial agents was done in vitro by modified Kirby-Bauer disc diffusion method, using fresh broth culture of isolates in Mueller Hinton Agar (MHA), following CLSI recommendations. A suspension matching $0.5 \mathrm{McFarland}$ standard $\left(1.5 \times 10^{8}\right.$ $\mathrm{cfu} / \mathrm{mL}$ ) was made in nutrient broth from the pure cultures of bacteria grown overnight on nutrient agar. MuellerHinton agar plates were inoculated by the lawn culture method using a sterile cotton swab. Commercially available antibiotic discs ampicillin $(10 \mu \mathrm{g})$, azithromycin $(15 \mu \mathrm{g})$, gentamicin $(10 \mu \mathrm{g})$, ofloxacin $(5 \mu \mathrm{g})$, polymyxin B $(300 \mu \mathrm{g})$, co-trimoxazole $(25 \mu \mathrm{g})$, nitrofurantoin (300 $\mu \mathrm{g})$, aztreonam $(30 \mu \mathrm{g})$, imipenem $(10 \mu \mathrm{g})$, meropenem $(10 \mu \mathrm{g})$, ceftazidime $(30 \mu \mathrm{g})$, cefepime $(30 \mu \mathrm{g})$ were used according to the nature of the organism and different zones of inhibition were measured and the results were interpreted as sensitive, intermediate or resistant by comparing with the standard interpretative table given by Hi Media laboratories. For screening of MRSA, cefoxitin $(30 \mu \mathrm{g})$ disc was used. Isolates showing an inhibition zone $\leq 21 \mathrm{~mm}$ around the cefoxitin disc were considered MRSA (CLSI, 2016). MDR-resistant organisms were differentiated based on their ability to resist three or more classes of antimicrobial agents (Magiorakos et al., 2012).

\section{Screening of extended-spectrum beta-lactamase (ESBL) production by phenotypic tests}

Ceftazidime and cefotaxime discs were placed on the Mueller Hinton agar plates and incubated at $35^{\circ} \mathrm{C}$ for 18 $24 \mathrm{~h}$. Probable ESBL-producers were the ones showing the zone of inhibition $\leq 22 \mathrm{~mm}$ for ceftazidime (CAZ)( 30 $\mu \mathrm{g})$ and $\leq 27 \mathrm{~mm}$ for cefotaxime (CTX) $(30 \mu \mathrm{g})$. A phenotypic confirmatory test was done for suspected ESBL producing microorganisms for which antibiotics combinations of ceftazidime + clavulanic acid (CAZ/CAC) $(30 / 10 \mu \mathrm{g})$ and cefotaxime + clavulanic acid (CTX/CTC) $(30 / 10 \mu \mathrm{g})$ were used (CLSI, 2016). An increase in the zone of inhibition by $\geq 5 \mathrm{~mm}$ around the discs containing cephalosporin with clavulanate over the discs containing cephalosporin alone were ESBL producers (CLSI, 2016).

\section{Statistical analysis}

Data analyses were performed using SPSS statistical software ver. 25.0 (SPSS Inc., Chicago, IL, USA). A chisquare test was used to determine the association between pulmonary infection with various attributes such as patients' age, gender, ethnic background, and presence of tuberculosis. The p-value $<0.05$ was assumed to be statistically significant for the analysis.

\section{RESULTS}

\section{Overall growth pattern in samples}

Among the 149 samples tested for microbial infection, $142(95.3 \%)$ samples showed at least one bacterial growth. Of those 142 growth positive samples, 127(89.4 $\%)$ showed mono-microbial growth and 15(10.6\%) accounted for poly-microbial growth.

\section{Association of bacterial growth with various attributes}

Out of the 142 growth positive samples, 92 (64.8\%) were from males and $50(35.2 \%)$ were from females. There was a strong association between gender and bacterial growth $(\mathrm{p}<0.05)$. While the age group 60-70 years accounted for maximum growth $44(30.9 \%)$ and on the other hand age group, 10-20 years showed the lowest growth rate $3(2.1 \%)$. Age and bacterial growth were significantly associated $(\mathrm{p}<0.05)$. Janajati ethnic group was encountered with maximum growth rate with 46 (32.4 $\%$ ) whereas least growth was accounted from the other ethnic groups $7(4.9 \%)$ but there was no association between ethnic group and bacterial growth. Among the 142 growth positive samples, $36(24.4 \%)$ were found to be co-infected with Mycobacterium tuberculosis, and the remaining $106(75.6 \%)$ were infected with bacteria other than MTB. But there was no significant association between Tuberculosis and bacterial growth. Among the total samples, $6(4.1 \%)$ were from those who tested positive with lung cancer (Table 1).

\section{Distribution of isolated bacteria}

A total of 157 bacterial growth was observed. Of those, $124(78.9 \%)$ were Gram negative and $33(21.1 \%)$ were Gram positive cocci. Among the Gram negative isolates, Pseudomonas aeruginosa was the frequently isolated bacterium $64(51.6 \%)$. Klebsiella pneumoniae was the second most frequently isolated bacteria 36 (29.1\%). Escherichia coli and Citrobacter koseri accounted for 20 $(16.1 \%)$ and $4(3.2 \%)$ respectively. Among 33 Gram positive cocci, Staphylococcus aureus accounted for 19 $(57.7 \%)$ and Streptococcus pneumoniae accounted for 14 $(42.3 \%)$, respectively, (Fig. 1).

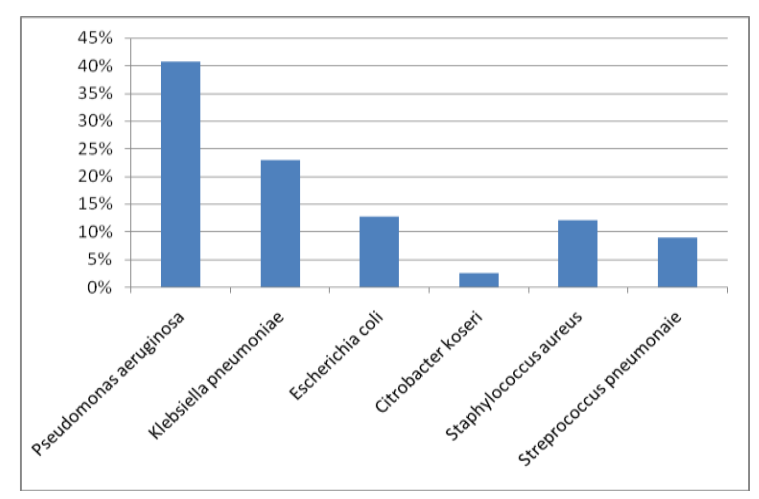

Fig. 1. Distribution of bacterial isolates 
Bacterial etiology of bronchoalveolar lavage fluid in tertiary care patients ...

Table 1. Association of bacterial growth with various attributes

\begin{tabular}{|c|c|c|c|c|c|}
\hline Variables & Category & Growth & No Growth & Total & p-Value \\
\hline \multirow{2}{*}{ Gender } & Male & $92(98.92 \%)$ & $1(1.08 \%)$ & 93 & \multirow{2}{*}{$0.007^{*}$} \\
\hline & Female & $50(89.28 \%)$ & $6(10.72 \%)$ & 56 & \\
\hline \multirow{8}{*}{ Age Group } & $0-10$ & $4(66.67 \%)$ & $2(33.33 \%)$ & 6 & \multirow{8}{*}{$0.041 *$} \\
\hline & $10-20$ & $3(100 \%)$ & 0 & 3 & \\
\hline & $20-30$ & $8(88.89 \%)$ & $1(11.11 \%)$ & 9 & \\
\hline & $30-40$ & $15(100 \%)$ & 0 & 15 & \\
\hline & $40-50$ & $17(100 \%)$ & 0 & 17 & \\
\hline & $50-60$ & $26(92.86 \%)$ & $2(7.14 \%)$ & 28 & \\
\hline & $60-70$ & $44(97.78 \%)$ & $1(2.22 \%)$ & 45 & \\
\hline & $70-80$ & $25(96.15 \%)$ & $1(3.85 \%)$ & 26 & \\
\hline \multirow{7}{*}{ Ethnicity } & Brahmin/Chhetri & $39(97.50 \%)$ & $1(2.50 \%)$ & 40 & \multirow{6}{*}{0.531} \\
\hline & Janajati & $46(97.87 \%)$ & $1(2.13 \%)$ & 47 & \\
\hline & Madhesi & $21(91.30 \%)$ & $28.70(\%)$ & 23 & \\
\hline & Muslim & $13(92.86 \%)$ & $1(7.14 \%)$ & 14 & \\
\hline & Dalit & $16(88.89 \%)$ & $2(11.11 \%)$ & 18 & \\
\hline & Others & $7(100 \%)$ & 0 & 7 & \\
\hline & Yes & $36(100 \%)$ & 0 & 36 & \multirow{2}{*}{0.126} \\
\hline TB infection & No & $106(93.81 \%)$ & $7(6.19 \%)$ & 113 & \\
\hline
\end{tabular}

*Significant at $5 \%$ level of significance

\section{Antibiotic susceptibility pattern (AST)}

The panel of 15 antibiotics discs was tested for all the isolates. Ampicillin and carbapenems were the drugs that were effective against all the isolates. Ampicillin was 100 $\%$ effective against $P$. aeruginosa and Gram-positive cocci while $92.8 \%$ effective against the Enterobacteriaceae family; whereas carbapenems were $100 \%$ effective against all the isolates. The least effective drug against $P$. aeruginosa was Gentamicin (1.5\%), which was also completely ineffective against the Enterobacteriaceae family and only $12.2 \%$ effective against Gram positive cocci. Amoxyclav, a combination of Amoxycillin and clavulanic acid, was effective against Gram positive cocci and $87.5 \%$ isolates of $P$. aeruginosa but only $54.2 \%$ effective against Enterobacteriaceae isolates (Table 2).

\section{Distribution of MDR and MRSA isolates}

Out of the total 157 isolates, $125(79.6 \%)$ isolates were MDR whereas the remaining $32(20.4 \%)$ isolates were non-MDR. Among the $19 \mathrm{~S}$. aureus isolates, 10 (52.6\%) were MRSA. $P$. aeruginosa dominated the MDR count accounting for $48.8 \%$ of total isolates. Following it was K. pneumoniae with $23.2 \%$ of isolates being MDR. The least MDR isolates were accounted for from $C$. koseri $(0.8$
$\%)$. Among Gram positive cocci, S. aureus accounted for $7.2 \%$ isolates and S. pneumoniae accounted for $4 \%$ among total MDR isolates (Fig. 2).

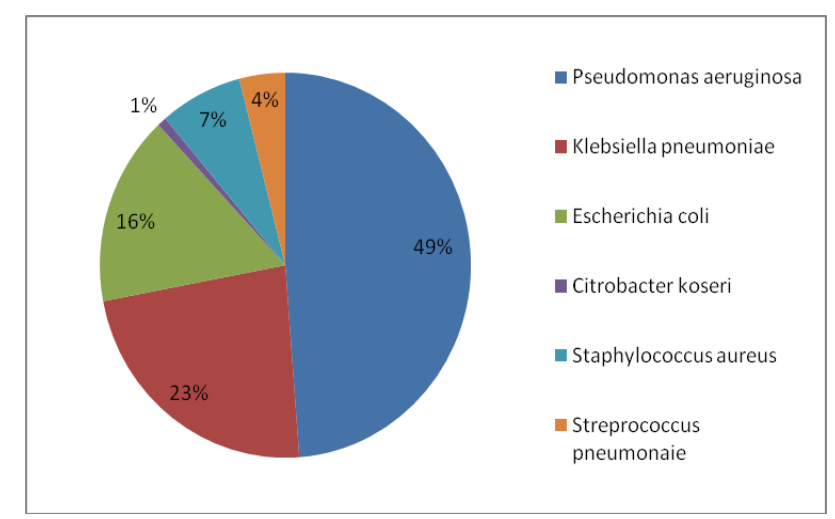

Fig. 2. Distribution of MDR isolates

\section{Frequency of ESBL-producing Enterobacteriaceae}

Among 60 enterobacteriaceae isolates, 31 (51.7 \%) isolates showed ESBL screening test positive. On performing the confirmatory test, $11(18.3 \%)$ isolates of $K$. pneumoniae, $8(13.3 \%)$ isolates of E. coli, and 2 (3.3 $\%)$ of $C$. koseri were found to be ESBL producers, as shown in (Table 3 ). 
Table 2. Antibiotic Susceptibility Pattern of the isolates

\begin{tabular}{llllllllll}
\hline & \multicolumn{3}{c}{ P. aeruginosa } & \multicolumn{3}{c}{ Enterobacteriaceae } & \multicolumn{3}{c}{ Gram positive Cocci } \\
\cline { 2 - 9 } Antibiotics & $\mathrm{S}$ & $\mathrm{I}$ & $\mathrm{R}$ & $\mathrm{S}$ & $\mathrm{I}$ & $\mathrm{R}$ & $\mathrm{S}$ & $\mathrm{I}$ & $\mathrm{R}$ \\
\hline Ampicillin & $100.0 \%$ & $0.0 \%$ & $0.0 \%$ & $92.8 \%$ & $7.2 \%$ & $0.0 \%$ & $100.0 \%$ & $0.0 \%$ & $0.0 \%$ \\
Amoxyclav & $87.5 \%$ & $9.3 \%$ & $3.1 \%$ & $54.2 \%$ & $30.0 \%$ & $15.8 \%$ & $100.0 \%$ & $0.0 \%$ & $0.0 \%$ \\
Azithromycin & $71.8 \%$ & $25.0 \%$ & $3.1 \%$ & $21.4 \%$ & $48.5 \%$ & $30.1 \%$ & $63.6 \%$ & $12.2 \%$ & $24.2 \%$ \\
Cefoxitin & $92.1 \%$ & $7.8 \%$ & $0.0 \%$ & $27.1 \%$ & $55.7 \%$ & $17.2 \%$ & $63.6 \%$ & $36.4 \%$ & $0.0 \%$ \\
Gentamicin & $1.5 \%$ & $26.5 \%$ & $71.8 \%$ & $0.0 \%$ & $31.4 \%$ & $68.6 \%$ & $12.2 \%$ & $0.0 \%$ & $87.8 \%$ \\
Ofloxacin & $6.2 \%$ & $23.4 \%$ & $70.3 \%$ & $10.0 \%$ & $20.0 \%$ & $70.0 \%$ & $0.0 \%$ & $63.6 \%$ & $36.4 \%$ \\
Polymyxin B & $6.2 \%$ & $32.8 \%$ & $60.9 \%$ & $2.8 \%$ & $44.2 \%$ & $53.0 \%$ & $24.2 \%$ & $24.2 \%$ & $51.6 \%$ \\
Co-trimoxazole & $85.9 \%$ & $14.1 \%$ & $0.0 \%$ & $78.5 \%$ & $12.8 \%$ & $8.7 \%$ & $63.6 \%$ & $0.0 \%$ & $36.4 \%$ \\
Nitrofurantoin & $57.8 \%$ & $12.5 \%$ & $29.7 \%$ & $36.7 \%$ & $5.0 \%$ & $58.3 \%$ & $54.5 \%$ & $36.4 \%$ & $9.1 \%$ \\
Aztreonam & $39.1 \%$ & $15.6 \%$ & $45.3 \%$ & $46.7 \%$ & $5.0 \%$ & $48.3 \%$ & $63.6 \%$ & $15.2 \%$ & $21.2 \%$ \\
Imipenem & $100.0 \%$ & $0.0 \%$ & $0.0 \%$ & $100.0 \%$ & $0.0 \%$ & $0.0 \%$ & $100.0 \%$ & $0.0 \%$ & $0.0 \%$ \\
Meropenem & $100.0 \%$ & $0.0 \%$ & $0.0 \%$ & $100.0 \%$ & $0.0 \%$ & $0.0 \%$ & $100.0 \%$ & $0.0 \%$ & $0.0 \%$ \\
Ceftazidime & $43.8 \%$ & $20.3 \%$ & $32.8 \%$ & $55.0 \%$ & $3.3 \%$ & $41.7 \%$ & $39.4 \%$ & $9.1 \%$ & $51.5 \%$ \\
Cefepime & $23.4 \%$ & $7.8 \%$ & $68.8 \%$ & $16.7 \%$ & $25.0 \%$ & $58.3 \%$ & $39.4 \%$ & $15.2 \%$ & $45.5 \%$ \\
\hline Sensitive, I= Intermediate. R= Resistant & & & & & & & &
\end{tabular}

Table 3. Frequency of ESBL-producing isolates

\begin{tabular}{lccc}
\hline Organism & $\begin{array}{l}\text { Signi- } \\
\text { ficant } \\
\text { growth }\end{array}$ & $\begin{array}{l}\text { Screen- } \\
\text { ing test } \\
\text { positive }\end{array}$ & $\begin{array}{l}\text { Confirmatory } \\
\text { test positive } \\
\text { (combination } \\
\text { disk method) }\end{array}$ \\
\hline K. pneumoniae & 36 & 17 & $11(30.6 \%)$ \\
E coli & 20 & 12 & $8(40.0 \%)$ \\
C. koseri & 4 & 2 & $2(50.0 \%)$ \\
\hline Total & 60 & 31 & $21(35.0 \%)$ \\
\hline
\end{tabular}

\section{DISCUSSION}

The diagnosis of respiratory tract diseases can be aided by bronchoscopy which is one of the best and frequently used techniques. By performing bronchoscopy, Bronchoalveolar lavage (BAL) fluid can be obtained for the disease diagnosis. BAL fluid is more sensitive and ensures for disease diagnosis. Besides this, bronchoscopy can be carried out in over-aged patients (Radha et al., 2014). The sample obtained using the BAL technique increases the efficacy of the actual pathogen detection by reducing the chances of contamination.

A total of 149 BAL fluid samples were collected and processed of which growth was seen in $(95.3 \%)$ of the samples. A study of diagnostic utility of bronchoalveolar lavage conducted in India found $88 \%$ of BAL fluid samples were growth positive (Radha et al., 2014). The study regarding the diagnostic utility of BAL with malignancies was performed by Hummel et al. (2008), which reported only $47 \%$ of the sample gave growth positive results. This high degree of variation depends highly upon the conditions in which patients are being treated with antimicrobial agents and also upon the cultural techniques. In this study, a total of 142 isolates were observed among which $94.4 \%$ were Gram-negative organisms, whereas $5.6 \%$ were Gram-positive organisms. Among 134 Gram-negative isolates, Pseudomonas aeruginosa $(51.6 \%)$ was the most prevalent isolate However, a different result was obtained in a study where Klebsiella pneumoniae $(39.4 \%)$ was the main isolate (Radha et al., 2014). Moreover, a study of the microbiology of bronchoalveolar lavage in infants reported Moraxella sp. and Streptococcus mitis as the major isolates (Palma-alaniz \& Ruelas-vargas, 2015). A high prevalence of $P$. aeruginosa in cases of pulmonary infection is due to its easy distribution in the air via any environmental sources like soil and water. Along with this, the transmission of bacteria is aided by the cough aerosols of other infectious patients (Woo et al., 2018; Thapa et al., 2016).

Out of the 142 growth positive samples, $64.8 \%$ were from males and $35.2 \%$ were from females. There was a strong association between gender and bacterial growth $(p<0.05)$. The higher occurrence of infection in a male could be because of the diverse exposure of males on various fields than females. All of the age groups after 30 years showed a higher rate of infectivity, including a $100 \%$ growth rate among the age group $30-40$ and $40-50$ years $(\mathrm{p}<0.05)$. 
This may be due to higher exposure in an environment which increases the risk of infection and also the weakening of immunity in the host during old age and this age group are more likely to suffer from pulmonary infections more due to the food habits like smoking and other malfunctions of the body like diabetes and blood pressure alterations (Blot et al., 2014). Janajati encountered a maximum percentage of the bacterial incidence than other ethnic groups followed by Brahmin/Chhetri ( $\mathrm{p}>0.05)$.

The high proportion of infection from the ethnic group can be attributed to the culture and tradition of these people along with the food and sanitary habits of the particular people. Among 149 samples, $25.4 \%$ showed AFB positive $(\mathrm{p}>0.05)$. This was in tune with a study with $24 \%$ AFB-positive samples (Radha et al., 2014). The proximity of bacteria with tuberculosis patients may be due to the weakened host immunity which help the successful colonization of the bacteria (Flynn, 2004). In various researches, it has been observed that there is a significant relationship between previous $\mathrm{TB}$ and lung cancer (Keikha \& Esfahani, 2018).

Antibiotic susceptibility testing of the isolated bacteria revealed that gentamicin, a commonly prescribed antibiotic, was resisted by many isolates. This was contrary to the research conducted in Poland (Semczuk et al., 2015). In terms of Gram positive bacteria, isolates were $100 \%$ sensitive to ampicillin whereas the majority of the isolates were resistant to gentamycin and polymyxin-B. In a study in Uganda, ampicillin was the least effective drug (82\%) (Kitara et al., 2011). In this study, out of the total 157 isolates, $79.6 \%$ isolates were MDR. This was in tune with the study which showed a majority of the isolated bacteria were resistant to antibiotics (Semczuk et al., 2015).

The occurrence of MDR isolates could be due to the evolving nature such as, simple nutritional requirement and ability to thrive in a wide range of temperature which assists gain resistance over many traditional and commonly used antibiotics. The problem of antibiotic resistance has been increasing rapidly and it has become a serious burden in the medical world. In addition, among 60 Enterobacteriaceae isolates, $35.0 \%$ were ESBL producers. The emergence of ESBL is mainly attributed to a resistant gene carried on an epidemic plasmid that can dessiminate and exist in the environment (Aibinu et al., 2007).

\section{CONCLUSION}

The current study reveals a high bacterial prevalence in the BAL fluid samples from the patients with pulmonary infections with the higher recovery of bacterial isolates in males and the age group 60-70 years. Out of the total 157 isolates, 79.6\% were MDR. In addition, among 60
Enterobacteriaceae isolates, $35.0 \%$ were ESBL producers. The emergence of multidrug-resistant bacteria, some of which being ESBL-producers, in BAL samples is worrisome and concerned authorities should consider this to abate their incidence and dissemination.

\section{ACKNOWLEDGEMENT}

The authors thank all the patients who provided us with BAL fluid samples and are also grateful to all the staff of BPKMCH, Bharatpur, and the microbiology laboratory of Birendra Multiple Campus, Bharatpur.

\section{REFERENCES}

Adhikari, S., Khadka, S., Sapkota, S., Adhikaree, N., Shrestha, B., \& Parajuli, A. (2020). Surgical site infections are the pool of antibiotic resistant bacteria: evidence from a tertiary hospital in Nepal. AntiInfective Agents, 18. https://doi.org/10.2174/22113525189992011021951 59

Adhikari, S., Khadka, S., Sapkota, S., Rana, J. C., Khanal, S., Neupane, A., \& Sharma, B. (2019). Prevalence and antibiograms of uropathogens from the suspected cases of urinary tract infections in Bharatpur hospital, Nepal. Journal of College of Medical Sciences-Nepal, 15(4), 260-266.

Aibinu, I., Nwanneka, T., \& Odugbemi, T. (2007). Occurrence of ESBL and MBL in clinical isolates of Pseudomonas aeruginosa from Lagos, Nigeria Ibukun. Journal of American Science, 3(4), 81-85.

Arancibia, F., Ewig, S., Martinez, J. A., Ruiz, M., Bauer, T., Marcos, M. A., ... Torres, A. (2000). Antimicrobial treatment failures in patients with community-acquired pneumonia: Causes and prognostic implications. American Journal of Respiratory and Critical Care Medicine, 162(1), 154-160.

Forbes, B.A., Sahm, D.F., Weissfeld, A.S. \& Bailey, W.R. (2007). Bailey and Scott's diagnostic microbiology $\left(12^{\text {th }}\right.$ ed.). St. Louius, MO: Elsevier Mosby, London.

Banstola, A. (2012). Issues and threats of Tuberculosis in Nepal. Online; https://www.ghdonline.org/ic/discussion/issues-andthreats-of-tuberculosis-in-nepal/

Bergey, D., Krieg, N. R., \& Holt, J. G. (1984). Bergey's manual of systematic bacteriology $\left(6^{\text {th }}\right.$ ed.). Baltimore, MD: Williams \& Wilkins, pp. 1984(C)1989.

Blot, S., Koulenti, D., Dimopoulos, G., Martin, C., Komnos, A., Krueger, W. A., \& Spina, G. (2014). Prevalence, risk factors, and mortality for ventilatorassociated pneumonia in middle-aged, old, and very 
old critically ill patients. Critical Care Medicine, 42, 601-609.

CLSI (2016). Performance standards for antimicrobial susceptibility testing $\left(26^{\text {th }}\right.$ ed.) Clinical and Laboratory Standards Institute, Wayne.

Dhillon, R. H. P., \& Clark, J. (2012). ESBLs: a clear and present danger. In Critical Care Research and Practice (Vol. 2012). https://doi.org/10.1155/2012/625170

Duwadi, K., Khadka, S., Adhikari, S., Sapkota, S., \& Shrestha, P. (2020). Bacterial etiology of wound exudates in tertiary care cancer patients and antibiogram of the isolates. Infectious Diseases: Research and Treatment, 13, 117863372095207. https://doi.org/10.1177/1178633720952077

Flynn, J. L. (2004). Immunology of tuberculosis and implications in vaccine development. Tuberculosis (Edinburgh, Scotland), 84(1-2), 93-101.

García-Elorriagaa, G., Palma-Alanizb, L., GarcíaBolañosc, C., Ruelas-Vargasd, C., Méndez-Tovarb, S., \& del Rey-Pinedae, G. (2015). Microbiology of bronchoalveolar lavage in infants with bacterial community-acquired pneumonia with poor outcome. Boletin Medico del Hospital Infantil de Mexico, 72(5), 307-312.

Gyawali, R., Khadka, R., Shrestha, B., \& Manandhar, S. (2020). Antimicrobial susceptibility patterns of Pseudomonas species isolated from various clinical samples at a tertiary care hospital. Journal of Institute of Science and Technology, 25(2), 49-54.

Haque, M. A. (2019). Seasonal incidence of communityacquired pneumonia: a retrospective study in a tertiary care hospital in Kathmandu, Nepal. Cureus, 11(12). https://doi.org/10.7759/cureus.6417

Henderson, A. J. W. (1994). Bronchoalveolar lavage. Archives of Disease in Childhood, 70(3), 167-169.

Hummel, M., Rudert, S., \& Hof, H. (2008). Diagnostic yield of bronchoscopy with bronchoalveolar lavage in febrile patients with hematologic malignancies and pulmonary infiltrates. Ann Hematol, 87, 291297.

Isenberg, H. D. (2016). Clinical microbiology procedures handbook. In A. L. Beer (Ed.), American Society of Miucrobiology ( $4^{\text {th }}$ ed.). ASM Press. https://doi.org/10.1128/9781555818814

Kahn, F. W., \& Jones, J. M. (1987). Diagnosing bacterial respiratory infection by bronchoalveolar lavage. Journal of Infectious Diseases, 155(5), 862-869.

Keikha, M., \& Esfahani, B. N. (2018). The relationship between tuberculosis and lung cancer. Advanced
Biomedical Research, 7, 58. https://doi.org/10.4103/abr.abr_182_17

Khadka, S., Adhikari, S., Rai, T., Ghimire, U., \& Parajuli, A. (2018). Bacterial contamination and risk factors associated with street-vended Panipuri sold in Bharatpur, Nepal. International Journal of Food Research, 5(3), 32-38. https://doi.org/10.33500/ijfr.2018.05.004

Kim, E. S., Kim, E. C., Lee, S. M., Yang, S. C., Yoo, C. G., Kim, Y. W., ... Yim, J. J. (2012). Bacterial yield from quantitative cultures of bronchoalveolar lavage fluid in patients with pneumonia on antimicrobial therapy. Korean Journal of Internal Medicine, 27(2), 156-162.

Kitara, L. D., Anywar, A. D., Acullu, D., Odongo-Aginya, E., Aloyo, J., \& Fendu, M. (2011). Antibiotic susceptibility of Staphylococcus aureus in suppurative lesions in Lacor Hospital, Uganda. African Health Sciences, 11 Suppl 1(Suppl 1), S34S39. $\quad$ Retrieved from https://pubmed.ncbi.nlm.nih.gov/22135642

Magazine, R., Rao, S., Chawla, K., \& Chogtu, B. (2013). Bacterial isolates from the bronchoalveolar lavage fluid of patients with pneumonia not responding to initial antimicrobial therapy. Sahel Medical Journal, 16(3), $\quad 102 . \quad \mathrm{https} / / /$ doi.org/10.4103/11188561.121914

Magiorakos, A., Srinivasan, A., Carey, R., Carmeli, Y., \& Falagas, M. (2012). Multidrug-resistant, extensively drug-resistant and pan drug-resistant bacteria: an international expert proposal for interim standard definitions for acquired resistance. Clinical Microbiology and Infection, 18(3), 268-281.

Meyer, K. C. (2007). Bronchoalveolar lavage as a diagnostic tool. Seminars in Respiratory and Critical Care Medicine, 28(5), 546-560.

Nasrin, S., Mitra, R., Mehdi, A., \& Fahime, E. (2010). Evaluation of extended spectrum betalactamase (ESBL) positive strains of Klebsiella pneumoniae and Escherichia coli in bacterial cultures. Iranian Journal of Pathology, 5(1), 34-39.

Önnberg, A., Mölling, P., Zimmermann, J., \& Söderquist, B. (2011). Molecular and phenotypic characterization of Escherichia coli and Klebsiella pneumoniae producing extended-spectrum $\beta$ lactamases with focus on CTX-M in a low-endemic area in Sweden. APMIS Journal of Pathology, Microbiology and Immunology, 119(4-5), 287-295.

Palma-alaniz, L., \& Ruelas-vargas, C. (2015). Microbiology of bronchoalveolar lavage in infants with bacterial community-acquired pneumonia with 
poor outcome. Boletín Médico del Hospital Infantil de México, 72(5), 307-312.

Radha, S., Afroz, T., Prasad, S., \& Ravindra, N. (2014). Diagnostic utility of bronchoalveolar lavage. Journal of Cytology/Indian Academy of Cytologists, 31(3), 136.

Regmi, R. S., Khadka, S., Sapkota, S., Adhikari, S., Dhakal, K. K., Dhakal, B., ... Kafle, S. C. (2020). Bacterial etiology of sputum from tuberculosis suspected patients and antibiogram of the isolates. BMC Research Notes, 13(1), 1-6.

Sapkota, S., Adhikari, S., Pandey, A., Khadka, S., Adhikari, M., Kandel, H., ... Pandey, A. (2019). Multi-drug resistant extended-spectrum betalactamase producing E. coli and Salmonella on raw vegetable salads served at hotels and restaurants in Bharatpur, Nepal. BMC Research Notes, 12(1), 516. https://doi.org/10.1186/s13104-019-4557-9

Sapkota, S., Khadka, S., Adhikari, S., Parajuli, A., Kandel, H., \& Regmi, R. S. (2020). Microbial diversity and antibiotic susceptibility pattern of bacteria associated with motorcycle helmets. International Journal of Microbiology, 2020. https://doi.org/10.1155/2020/8877200

Semczuk, K., Dmeńska, H., Dzierżanowska-Fangrat, K., Dzierżanowska, D., Fronc, B., \& Szyszkiewicz, A. (2015). 104 antimicrobial susceptibility of Pseudomonas aeruginosa (PA) and Staphylococcus aureus (SA) isolated from CF patients over 13 years. Journal of Cystic Fibrosis, 14, S83. https://doi.org/https://doi.org/10.1016/S15691993(15)30281-2

Thapa, E., Thapa, R., Singh, A., Pokharel, B., \& Devkota, U. (2016). Antibiotic resistance pattern of bacterial isolates from post-tracheostomised patients attending tertiary care hospital in Nepal. Journal of Institute of Science and Technology, 21(1), 129-132.

Woo, T., Lim, R., Surette, M., Waddell, B., Bowron, J., Somayaji, R., ... Parkins, M. (2018). Epidemiology and natural history of Pseudomonas aeruginosa airway infections in non-cystic fibrosis bronchiectasis. ERJ Open Research, 4, 162-2017. 